\title{
Telehome monitoring of symptoms and lung function in children with asthma
}

\author{
Audrey Fossati ${ }^{1}$, Caroline Challier ${ }^{1}$, Aman Dalhoumi ${ }^{2}$, Javier Rose ${ }^{3}$, François Galodé ${ }^{4}$, and \\ Michael Fayon ${ }^{4}$ \\ ${ }^{1} \mathrm{CHU}$ de Bordeaux \\ ${ }^{2} \mathrm{CH}$ Agen \\ ${ }^{3}$ Republique des Seychelles \\ ${ }^{4}$ CHU Bordeaux GH Pellegrin
}

April 13, 2021

\begin{abstract}
Background: The ability to perceive bronchial obstruction is variable in asthma. This is one of the main causes of inaccurate asthma control assessment, on which therapeutic strategies are based. Objective: Primary: To evaluate the ability of a clinical and spirometric telemonitoring device to characterize symptom perception profile in asthmatic children. Secondary: To evaluate its impact on asthma management (control, treatment, respiratory function variability) and the acceptability of this telemonitoring system. Method: 26 asthmatic children aged 6-18 years equipped with a portable spirometer and a smartphone application were monitored remotely for 3 months. Clinical and spirometric data were automatically transmitted to a secure internet platform. A medical team contacted the patient to optimize management. Three physicians blindly and independently classified the patients according to their perception profile. The impact of telemonitoring on the quantitative data was assessed at the beginning (T0) and end (T3 months) of telemonitoring, using matched statistical tests. Results: Patients could initially be classified according to their perception profile, with a concordance between the 3 observers of $64 \%$ (kappa coefficient: 0.55 , $95 \%$ CI $[0.39 ; 0.71])$. After further discussion, a consensus was reached and resulted in $97 \%$ concordance (kappa coefficient: $0.97,95 \%$ CI $[0.91 ; 1.00])$. There was a trend towards improvement in the ACT score, and a significant $>40 \%$ decrease in FEV1 and PEF variability, with good acceptance of the device. Conclusion: Clinical and spirometric telehome monitoring is applicable and can help define the perception profile of bronchial obstruction in asthmatic children. The device was generally well accepted.
\end{abstract}

\section{Telehome monitoring of symptoms and lung function in children with asthma}

Audrey FOSSATI MD ${ }^{1}$, Caroline CHALLIER MD ${ }^{1}$, Aman Allah DALHOUMI MD ${ }^{2}$, Javier ROSE MD ${ }^{3}$, François GALODE MD ${ }^{1}$, Michael FAYON MD, $\mathrm{PhD}^{1,4,5}$.

${ }^{1}$ CHU de Bordeaux, Pediatrics Department, Pediatric Pulmonology, Bordeaux, France

${ }^{2}$ Centre Hospitalier d'Agen-Nérac, Pediatrics Department, Agen, France

${ }^{3}$ Seychelles Hospital, Victoria, Mahé, Republic of Seychelles, Indian Ocean

${ }^{4}$ University of Bordeaux, Bordeaux Cardio-Thoracic Research Center, INSERM U1045, Bordeaux Imaging Center, Bordeaux, France

${ }^{5}$ INSERM, Centre d'Investigation Clinique (CIC1401), Bordeaux, France

\section{Correspondence}


Audrey FOSSATI,

Pediatrics Department,

CHU de Bordeaux, Hôpital Pellegrin-Enfants,

Place Amélie Raba Léon, 33000 Bordeaux, France.

Email: audrey.fossati@chu-bordeaux.fr; audrey.fossati92@gmail.com

\title{
KEYWORDS
}

Asthma, Child, Telemonitoring, Spirometry, Symptom perception, Profile

Short Version Title: Home monitoring in pediatric asthma

\begin{abstract}
Background: The ability to perceive bronchial obstruction is variable in asthma. This is one of the main causes of inaccurate asthma control assessment, on which therapeutic strategies are based.

Objective: Primary: To evaluate the ability of a clinical and spirometric telemonitoring device to characterize symptom perception profile in asthmatic children. Secondary: To evaluate its impact on asthma management (control, treatment, respiratory function variability) and the acceptability of this telemonitoring system.
\end{abstract}

Method: 26 asthmatic children aged 6-18 years equipped with a portable spirometer and a smartphone application were monitored remotely for 3 months. Clinical and spirometric data were automatically transmitted to a secure internet platform. A medical team contacted the patient to optimize management. Three physicians blindly and independently classified the patients according to their perception profile. The impact of telemonitoring on the quantitative data was assessed at the beginning (T0) and end (T3 months) of telemonitoring, using matched statistical tests.

Results: Patients could initially be classified according to their perception profile, with a concordance between the 3 observers of $64 \%$ (kappa coefficient: $0.55,95 \%$ CI [0.39; 0.71]). After further discussion, a consensus was reached and resulted in $97 \%$ concordance (kappa coefficient: $0.97,95 \% \mathrm{CI}[0.91 ; 1.00]$ ). There was a trend towards improvement in the ACT score, and a significant $>40 \%$ decrease in FEV1 and PEF variability, with good acceptance of the device.

Conclusion: Clinical and spirometric telehome monitoring is applicable and can help define the perception profile of bronchial obstruction in asthmatic children. The device was generally well accepted.

\section{INTRODUCTION}

Telemedicine has been a rapidly growing field over the last twenty years, particularly since the COVID19 epidemic. Its importance has been recognized both nationally and internationally. The World Health Organization (WHO) published in 2019 its first recommendations on the use of digital health ${ }^{1}$. In France, the telemedicine deployment plan published by the Haute Autorité de Santé (HAS) in 2013 has defined the management of chronic pathologies using telemedicine as one of the 5 national priorities ${ }^{2}$. Telemonitoring in particular is increasingly used to monitor chronic patients, and allows the recording of clinical or technical indicators at home with the identification of alerts ${ }^{3}$. These data are interpreted remotely by a medical team, who can then provide personalized care.

Asthma is the most common chronic pathology in children, and its level of control remains insufficient ${ }^{4}$. According to international guidelines, the level of asthma control is determined based on symptom control over the last four weeks reported by children and their parents at the time of consultations, and on spirometric examinations performed on an ad hoc basis ${ }^{5}$. However, according to the AIRE (Asthma Insights and Reality in Europe) study carried out in 2002, the parents' perception of asthma control is erroneous: in fact, $61 \%$ of parents of children with severe persistent asthma considered that their child's asthma was well controlled ${ }^{6}$. Moreover, the ability to perceive the onset and severity of symptoms varies among children and depends 
on multifactorial causes and very complex and largely undefined psycho-physiological mechanisms ${ }^{7,8}$. The use of peak flow meters is recommended to help the patient objectify the degree of bronchial obstruction, but previous studies have shown that there is only a weak correlation between objective measures of respiratory distress and the subjective dyspnea sensation described by the patient ${ }^{9-11}$. Some patients will report significant discomfort with minimal bronchoconstriction, leading the clinician to question whether these symptoms are due to bronchospasm, anxiety or other factors ${ }^{12}$; and others will not report symptoms even in the presence of severe obstruction ${ }^{13}$.

With this in mind, Brouwer et al. conducted a study in 36 children with mild to moderate persistent asthma who electronically recorded Peak Expiratory Flow (PEF) and Forced Expiratory Volume in one second (FEV1) twice daily for 3 months using a home spirometer ${ }^{14}$. The results showed a poor correlation between the spirometric data and clinical disease activity scores. Importantly, the authors were able to distinguish four perception profiles in the asthmatic child: poor perceivers (no symptoms in the presence of severe obstruction); good perceivers (correlation between symptoms and bronchial obstruction); excessive perceivers (many symptoms with no or minimal obstruction) and anarchic perceivers (no correlation between symptoms and obstruction). Since symptom reporting is an integral part of therapeutic management of asthma (control scores), this may have implications for clinical and therapeutic approaches for these patients. Under-perception may delay the diagnosis and treatment of exacerbations, resulting in a greater risk of morbidity and mortality ${ }^{15,16}$. Conversely, excessive perception of symptoms may lead to overuse of medication and frequent recourse to consultations ${ }^{17}$. The lack of precise determination of these profiles could explain why some studies have not demonstrated a net benefit related to the application of telemonitoring in childhood asthma, particularly in terms of reduction of medical treatments ${ }^{18}$.

Therefore, the current study was conducted to assess whether the perception profile of children with asthma can be routinely identified using home telemonitoring of clinical symptom and FEV1. In addition, we evaluated the impact of home telemonitoring on asthma management (control, therapeutic optimization, spirometric signal variability), as well as the acceptability and barriers to the use of this mobile health care system.

\section{MATERIAL AND METHODS}

\section{Context and ethics}

This was a retrospective study that analyzed data from asthmatic children and adolescents followed at the Children's Hospital of the Centre Hospitalier Universitaire (CHU) of Bordeaux and the Seychelles Hospital between December 2018 and January 2021. The children and their parents were informed of the objectives of the study and written informed consent for the use of their data was obtained. In view of the documents at its disposal, the Publication Group of the Ethics Committee of the CHU of Bordeaux issued a favorable opinion on the publication of this research work (Opinion CE-GP-2021/12).

\section{Sample}

The study included 26 asthmatic children and adolescents aged 6 to 18 years old. The inclusion criteria were: asthma diagnosed by a physician for more than 6 months, moderate to severe persistent asthma according to the Global Initiative for Asthma (GINA) (treatment level [?] 3), having a home connected tool (tablet and/or smartphone), being able to perform correct spirometry. The exclusion criteria were any other pathology responsible for respiratory symptoms (cystic fibrosis, primary ciliary dyskinesia, chronic obstructive pulmonary disease...).

\section{Objectives}

The primary objective was to evaluate the device's ability to characterize patients according to Brouwer's profiles based on data collected by the mobile health platform. The secondary objectives were to study, overall and according to the Brouwer profile of the children: the role of home telemonitoring on asthma control, treatment levels (GINA steps), lung function and its variability, and the satisfaction of children and parents regarding these telemonitoring devices and process. 


\section{Conduct of the study}

As part of routine care, patients received a free electronic spirometer Spirobank Smart(r) (MIR company, Langlade, France). It enables the measurement of FEV1, PEF, and FEF25-75 (Forced Expiratory Flow at $25-75 \%$ of the vital capacity) which are then transmitted in real time via the free application Pneumotel uploader(r) (company LAMIRAU Ingenierie, Langlade, France) installed on the patient's smartphone, to the central and secure Pneumotel(r) internet platform. The application also allows the patient to enter his/her clinical symptoms. The clinical symptoms monitored were those related to an exacerbation: wheezing in the chest, shortness of breath, difficulty speaking, more coughing than usual; and those of asthma control according to GINA guidelines: activity limitation, taking bronchodilators (e.g. salbutamol), signs of daytime asthma, nocturnal awakening due to asthma. In a subgroup of patients, SpO2 (pulsed oxygen saturation) and heart rate were also monitored.

The monitoring process began with a 10-day observation phase, during which the patient made twice-daily spirometric recordings at home, as well as his/her clinical symptoms. In the absence of signs of exacerbation, the best FEV1 value obtained during this period was taken as a reference. Once the observation phase was over, FEV1 and clinical signs were performed at least twice a week outside of exacerbation phases and daily if the patient thought he had signs of exacerbation. In case of worsening (at least one clinical sign of exacerbation and/or uncontrolled asthma ([?] 3 items of poor GINA control) and/or a drop in FEV1 [?] $30 \%$ compared to the reference value ${ }^{19}$ ), the physician received an alert by e-mail and Short Message Service (SMS). They then contacted the patient by phone call or e-mail within 24 hours for a real assessment of the situation and to optimize management. The data analyzed included the recordings made during 3 months of follow-up for each patient.

Personal and family history, asthma characteristics, Asthma Control Test (ACT) score and treatments were collected from the computerized hospital medical records. A semi-structured interview was conducted between the physician and the patient and his/her parents after 3 months of use of the device to assess the acceptability and barriers to the use of Spirobank Smart(r). The After Scenario Questionnaire (ASQ) was also completed to qualitatively assess satisfaction with this connected device ${ }^{20}$.

\section{Statistical analysis}

Data are reported as mean + standard deviation or median [interquartile range IQR1; IQR3]. Statistical analysis was performed using PRISM software (GraphPad Software, San Diego, California 92108). Regarding the identification of the perception profile, 3 physicians (observer 1: M.F., 35 years of post-thesis experience; observer 2: F.G., 6 years of post-thesis experience; observer 3: A.F., in thesis year) classified the patients blindly and independently according to 5 categories: "good perceiver", "poor perceiver", "anarchic perceiver", "excessive perceiver" or "unclassifiable". The concordance of this classification between the 3 physicians was then evaluated according to the Randolph's Kappa coefficient method, before and after a collegial discussion of the cases (Delphi method). Agreement by pairs was assessed using Cohen's Kappa coefficient. The variability of FEV1 and PEF was calculated for each patient over the first 15 and last 15 days of the study using the following formula: (maximum value - minimum value) / mean of the 2 values. The quantitative variables for the two groups were compared by the Student's t-test (or Mann and Whitney for non-Gaussian data). The non-continuous variables were compared by the chi-squared test or two-tailed Fischer exact test (non-parametric). A $\mathrm{p}<0.05$ was considered a statistically significant difference for all tests.

The qualitative study regarding the satisfaction with the telemonitoring device was conducted according to a semio-pragmatic phenomenological interpretative method. All the interviews were transcribed word for word, and then analyzed to identify themes. A triangulation of the qualitative data was carried out.

\section{RESULTS}

\section{Study flow diagram}

The flow chart is shown in Figure 1. 


\section{Demographic characteristics of the study population}

Demographic characteristics of the study population are shown in Table 1.

\section{Main objective: Brouwer's asthma profile}

After evaluating each patient's profile independently and blindly, based on the criteria reported by Brouwer et al., the overall concordance between the 3 observers was $64 \%$. Randolph's kappa coefficient was 0.55 [0.39; 0.71]. When assessed in pairs, Cohen's kappa coefficient ranged from 0.33 to 0.61 (Figure 2, E-Table 1).

After the Delphi approach (consensus among observers), the final overall agreement was $97 \%$ with a Randolph's kappa coefficient of $0.97[0.91 ; 1.00]$. The percentage of patients that could be classifiable into a specific profile was $88 \%(23 / 26)$. $38 \%$ were anarchic perceivers $(10 / 26), 27 \%$ were poor perceivers $(7 / 26)$, $15 \%$ were good perceivers $(4 / 26)$ and $8 \%$ were excessive perceivers $(2 / 26)$. Two patients were defined as "unclassifiable" because the first patient did not provide enough data, and the quality of the spirometry recordings of the second patient was considered to be poor. There was no consensus for one child (E-Figure 1 ; E-Table 2).

\section{Secondary objectives}

\section{Asthma control}

There was a non-significant trend towards improvement in the ACT score between baseline (median 16 [14; $20]$ ) and the end of the study (median $20[15 ; 23]$ ) (Figure 3). The change in the ACT scores according to the patients' perception profile is represented in E-Figure 2.

\section{Therapeutic optimization}

The distribution of treatment steps from the beginning to the end of the study is shown in Figure 4 . The distribution according to the patients' perception profile is represented in E- Figure 3.

\section{FEV1 and PEF variability}

The mean FEV1 for the first 15 days $(1.49 \mathrm{~L} / \mathrm{s}+0.64)$ did not differ significantly from the mean for the last 15 days $(1.48 \mathrm{~L} / \mathrm{s}+0.66)$. The mean PEF for the first 15 days $(3.15 \mathrm{~L} / \mathrm{s}+1.42)$ did not differ significantly from the mean for the last 15 days $(3.22 \mathrm{~L} / \mathrm{s}+1.61)$.

FEV1 variability decreased from a median of $75.6 \%[42.6 ; 87.9]$ at the beginning of the study to $35.6 \%$ [22.7; $73.4]$ at the end of the study $(\mathrm{p}=0.006)$ (Figure 5a). PEF variability decreased from a median of $90.2 \%[49.6$; $112.7]$ at baseline to $44.4 \%[19.3 ; 97.5]$ at the end of the study ( $\mathrm{p}=0.03)$ (Figure $5 \mathrm{~b})$.

\section{Tool observance and acceptability}

During the first 10 days, $73 \%$ of patients $(19 / 26)$ recorded at least half of the 20 expected measurements (E-Figure 4). After these 10 days, $73 \%$ of patients (19/26) achieved the expected minimum of 2 weekly recordings.

Children and their parents were generally very satisfied with Spirobank Smart(r) follow-up according to the ASQ (After Scenario Questionnaire) (E-Figure 5).

\section{Qualitative analysis}

A total of 15 children and 17 parents were included in the qualitative analysis at the end of the study. When asked, "Were you satisfied with the Spirobank Smart(r)?", the entire sample was satisfied with the tool and the follow-up. Regarding the positive points reported by children and parents, the system was particularly appreciated for its playful and intuitive aspect. In addition, some children and parents reported a better perception of the severity of asthma exacerbations thanks to the FEV1 and PEF values displayed on the mobile application. Parents expressed a feeling of comfort and reassurance thanks to the telemonitoring. They felt that the monitoring was close without appearing over-medicalized. To the question: "Did you find the device too medicalized?" all but one of the parents answered in the negative. Nevertheless, some parents 
expressed their anxiety whenever the medical team did not respond quickly enough or if the child left home without his portable spirometer. Half of the parents surveyed did not find the device constraining, but the need to perform the measurement daily was experienced as a constraint by some children. The length of the expired breaths required to record technically good spirometric tests also discouraged some children.

\section{DISCUSSION}

The current study showed that clinical and spirometric home telemonitoring was applicable. In the majority of cases, it was possible to define the profile of clinical perception of bronchial obstruction in asthmatic children, but collegial discussion among professionals to reach an acceptable level of agreement was required. In addition, there was a non-significant trend towards improved asthma control (ACT score) after 3 months of follow-up, as well as a significant decrease in FEV1 and PEF variability. The observed changes in the distribution of treatment levels are the result of a therapeutic decision based on a better understanding of the perception profile. Based on the telemonitoring data, treatment may have been decreased in some well-controlled children, and increased in others with truly severe asthma. The device was well accepted by the asthmatic children and their family.

Among the 23 out of 26 children who could be classified, the distribution of perception profiles was as follows: anarchic perceivers $(44 \%)>$ poor perceivers $(30 \%)>$ good perceivers $(17 \%)>$ excessive perceivers $(9 \%)$. The study of Brouwer et al. on 36 asthmatic children found the following distribution: poor perceivers $(36 \%)$ $>$ anarchic perceivers $(25 \%)>$ good perceivers $(19.5 \%)=$ excessive perceivers $(19.5 \%)$. These differences could be explained by the severity of the asthma being monitored (less severe in their population) or the way in which symptoms are recorded (written diary versus electronically). The existence of different perception profiles could explain why some studies have not demonstrated a net benefit from the application of telemonitoring of childhood asthma ${ }^{21}$, and could have an implication in the design of clinical trials by selecting a certain category of perception profile as the study population. The classification of patients according to their perception profile of bronchial obstruction could also have practical applications by enabling healthcare professionals to propose personalized management to promote optimal disease control. Patients defined as poor perceivers could more easily have their background treatment increased, and conversely a decrease in treatment could be envisaged in overperceiver patients. This aid to therapeutic adaptation was one of the major expectations of the patients in our study. Finally, it could make it possible to target the profiles that would benefit most from objective measurements of airway obstruction over the long term. Once a patient has been identified as a good perceiver, its follow-up could be simplified based on the evaluation of symptoms alone. On the contrary, patients who are poor perceivers could benefit from the use of a peak flow meter or a portable spirometer at home over the long term.

Children and their parents were generally very satisfied with the follow-up. They appreciated the playfulness and ease of use of the device. This enthusiasm for connected devices is part of the era of smart-medicine where more and more devices, gadgets, and applications are being offered to patients ${ }^{22}$. However, the clinical effectiveness of most of these technology-based strategies is not evidence-based and further studies are needed to assess their reliability. Most parents appreciated having access to their children's spirometry results. This highlights patients' desire to be actors in their own therapeutic management, a desire that increases with the rate of health crises ${ }^{23}$. Nevertheless, they still reported a feeling of reassurance from this close medical follow-up with the Spirobank Smart(r), even to the point of apprehension when it was stopped. Despite the advice given to parents to be careful to maintain their usual lifestyle, the introduction of the device inevitably created a need, even a form of dependency.

Three patients refused Spirobank Smart(r) follow-up and one patient did not take any measurements at home. The reasons cited were a lack of time and the constraint of using a new device in addition to daily treatment. The implementation of a new therapeutic object in the patient's daily life should therefore not add too great of a burden ${ }^{24}$. The recommended frequency of use of the device should also be taken into account. Indeed, some children in our study mentioned the constraint of having to perform the measurement daily during the first ten days. To stimulate compliance over the long term, automatic reminders were sent out after 7 days without a recorded value. A decrease in compliance is found in longer-term studies, such as in 
the Cote study where compliance with daily spirometry measurements dropped from $63 \%$ in the first month to $33 \%$ at 12 months ${ }^{25}$. On the other hand, a decrease in technical efficiency during the 3 months of follow-up was observed in some patients in our study using flow-volume curves, although other studies do not report a decrease in the technical quality of maneuvers over time ${ }^{26}$. Moreover, this device is not adapted to children under 6 years old because it requires to know how to perform spirometric measurements of good quality. Regular sessions of therapeutic education in the classroom or in e-TPE (Therapeutic Patient Education) are therefore necessary to reinforce compliance and technique. To compensate for age and technical requirements, the usefulness of remote monitoring devices that do not require the active participation of the patient should be studied. Lastly, the lack of significant improvement in asthma control could be partly explained by poor adherence to treatment, one of the major causes of uncontrolled asthma ${ }^{27}$. The combination of this system with the use of connected inhalers allowing the collection of adherence data on the same platform could be an even more comprehensive remote monitoring tool ${ }^{28}$.

In conclusion, the current study shows that clinical and spirometric home telemonitoring is applicable and can be used to characterize the perception profile of bronchial obstruction in asthmatic children to help obtain better control and adapted therapeutic management. Research projects studying the role of such a telemonitoring system on a longer term basis and including other clinical evaluation criteria such as quality of life, unscheduled visits and hospitalization remain to be conducted.

\section{FUNDING}

This project was supported by a financial grant by AADAIRC (http://www.aadairc.com/) which enabled us to purchase the portable spirometers and oximeters, logistical support from MIR France and Lamirau Ingenierie for this project and financial support for a at-a-distance e-therapeutic education project in asthmatic children (Novartis).

\section{AUTHOR CONTRIBUTIONS}

Caroline Challier: conceptualization; methodology; investigation; formal analysis. Aman A. Dalhoumi: conceptualization; methodology. Michael Fayon: conceptualization; methodology; funding acquisition; investigation; formal analysis; writing - review \& editing. Audrey Fossati: conceptualization; investigation; writing - original draft preparation; formal analysis; writing - review \& editing. Francois Galode: formal analysis. Javier Rose: investigation; project administration.

\section{REFERENCES}

1. World Health Organization. 2019. Draft global strategy on digital health 2020-2024. Geneva: World Health Organization.

2. Haute Autorite de Sante. 2013. Efficience de la telemedecine : etat des lieux de la litterature internationale et cadre d'evaluation. Rapport d'evaluation medico-economique. Paris: Haute Autorite de Sante.

3. Hanlon P, Daines L, Campbell C, McKinstry B, Weller D, Pinnock H. Telehealth Interventions to Support Self-Management of Long-Term Conditions: A Systematic Metareview of Diabetes, Heart Failure, Asthma, Chronic Obstructive Pulmonary Disease, and Cancer. J Med Internet Res. 2017;19:172.

4. de Blic J, Boucot I, Pribil C, Robert J, Huas D, Marguet C. Control of asthma in children: still unacceptable? A French cross-sectional study. Respir Med. 2009;103:1383-1391.

5. Global Initiative for Asthma. 2020. Global Strategy for Asthma Management and Prevention. USA: Global Initiative for Asthma.

6. Blanc FX, Postel-Vinay N, Boucot I, De Blic J, Scheinmann P. The AIRE Study: data analysis of 753 European children with asthma. Rev Mal Respir. 2002;19:585-592.

7. Douros K, Boutopoulou B, Papadopoulos M, Fouzas S. Perception of dyspnea in children with asthma. Front Biosci (Elite Ed). 2015;7:469-477. 
8. Still L, Dolen WK. The Perception of Asthma Severity in Children. Curr Allergy Asthma Rep. 2016;16:50.

9. Douros K, Boutopoulou B, Priftis KN. Blunted perception of dyspnea in asthmatic children: A potential misleading criterion. World J Clin Pediatr. 2015;4:38-40.

10. Kendrick AH, Higgs CM, Whitfield MJ, Laszlo G. Accuracy of perception of severity of asthma: patients treated in general practice. BMJ. 1993;307:422-424.

11. Russell NJ, Crichton NJ, Emerson PA, Morgan AD. Quantitative assessment of the value of spirometry. Thorax. 1986;41:360-363.

12. Feldman JM, Steinberg D, Kutner H, Eisenberg N, Hottinger K, Sidora-Arcoleo K, et al. Perception of pulmonary function and asthma control: the differential role of child versus caregiver anxiety and depression. J Pediatr Psychol. 2013;38:1091-1100.

13. Baker RR, Mishoe SC, Zaitoun FH, Arant CB, Lucas J, Rupp NT. Poor perception of airway obstruction in children with asthma. J Asthma. 2000;37:613-624.

14. Brouwer AFJ, Roorda RJ, Brand PLP. Home spirometry and asthma severity in children. Eur Respir J. 2006;28:1131-1137.

15. Magadle R, Berar-Yanay N, Weiner P. The risk of hospitalization and near-fatal and fatal asthma in relation to the perception of dyspnea. Chest. 2002;121:329-333.

16. Rhee H, Belyea MJ, Halterman JS. Adolescents' Perception of Asthma Symptoms and Health Service Utilization. J Pediatr Health Care. 2011;25:105-113.

17. Barnes PJ, Szefler SJ, Reddel HK, Chipps BE. Symptoms and perception of airway obstruction in asthmatic patients: Clinical implications for use of reliever medications. J Allergy Clin Immunol. 2019;144:11801186.

18. Deschildre A, Beghin L, Salleron J, Iliescu C, Thumerelle C, Santos C, et al. Home telemonitoring (forced expiratory volume in $1 \mathrm{~s}$ ) in children with severe asthma does not reduce exacerbations. Eur Respir J. 2012;39:290-296.

19. Honkoop PJ, Taylor DR, Smith AD, Snoeck-Stroband JB, Sont JK. Early detection of asthma exacerbations by using action points in self-management plans. Eur Respir J. 2013;41:53-59.

20. Lewis JR. IBM computer usability satisfaction questionnaires: Psychometric evaluation and instructions for use. International Journal of Human-Computer Interaction. 1995;7(1):57-78.

21. Kew KM, Cates CJ. Home telemonitoring and remote feedback between clinic visits for asthma. Cochrane Database Syst Rev. 2016;(8).

22. Katwa U, Rivera E. Asthma Management in the Era of Smart-Medicine: Devices, Gadgets, Apps and Telemedicine. Indian J Pediatr. 2018;85(9):757-762.

23. Mougeot F, Robelet M, Rambaud C, Occelli P, Buchet-Poyau K, Touzet S, et al. Emergence of the patient-actor in patient safety in France. A narrative review in social sciences and public health. Sante Publique. 2018;30(1):73-81.

24. Simpson AJ, Honkoop PJ, Kennington E, Snoeck-Stroband JB, Smith I, East J, et al. Perspectives of patients and healthcare professionals on mHealth for asthma self-management. Eur Respir J. 2017;49(5).

25. Cote J, Cartier A, Malo JL, Rouleau M, Boulet LP. Compliance with peak expiratory flow monitoring in home management of asthma. Chest. 1998;113(4):968-972.

26. Wensley DC, Silverman M. The quality of home spirometry in school children with asthma. Thorax. 2001;56(3):183-185. 
27. Basharat S, Jabeen U, Zeeshan F, Bano I, Bari A, Rathore AW. Adherence to asthma treatment and their association with asthma control in children. J Pak Med Assoc. 2018;68(5):725-728.

28. Jochmann A, Artusio L, Jamalzadeh A, Nagakumar P, Delgado-Eckert E, Saglani S, et al. Electronic monitoring of adherence to inhaled corticosteroids: an essential tool in identifying severe asthma in children. Eur Respir J. 2017;50(6).

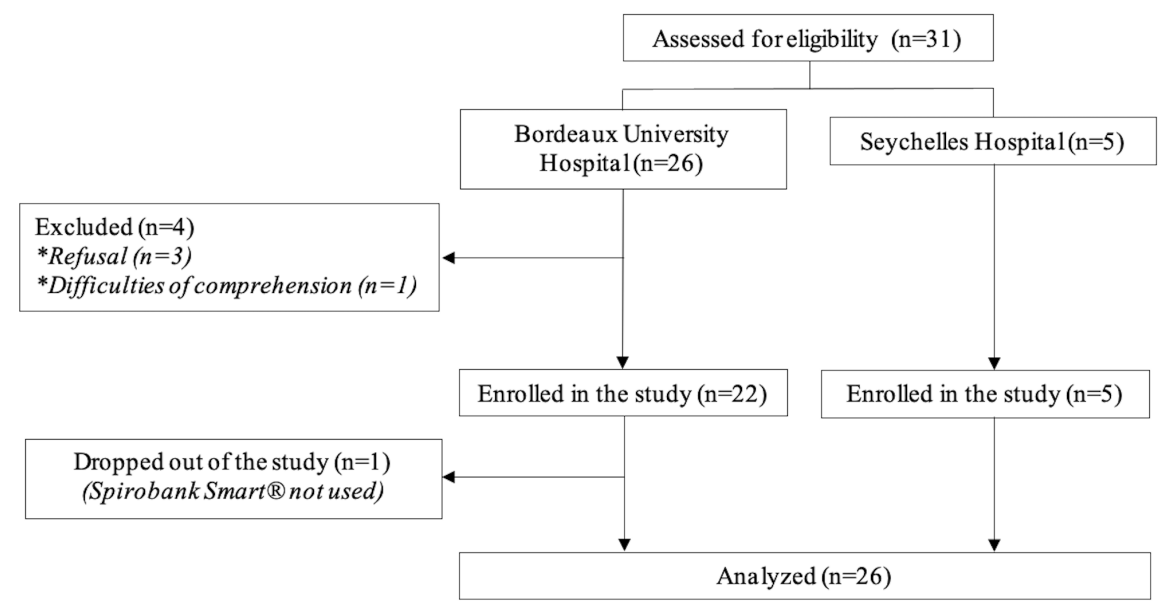

\section{Hosted file}

Tables.pdf available at https://authorea.com/users/407585/articles/517860-telehomemonitoring-of-symptoms-and-lung-function-in-children-with-asthma 


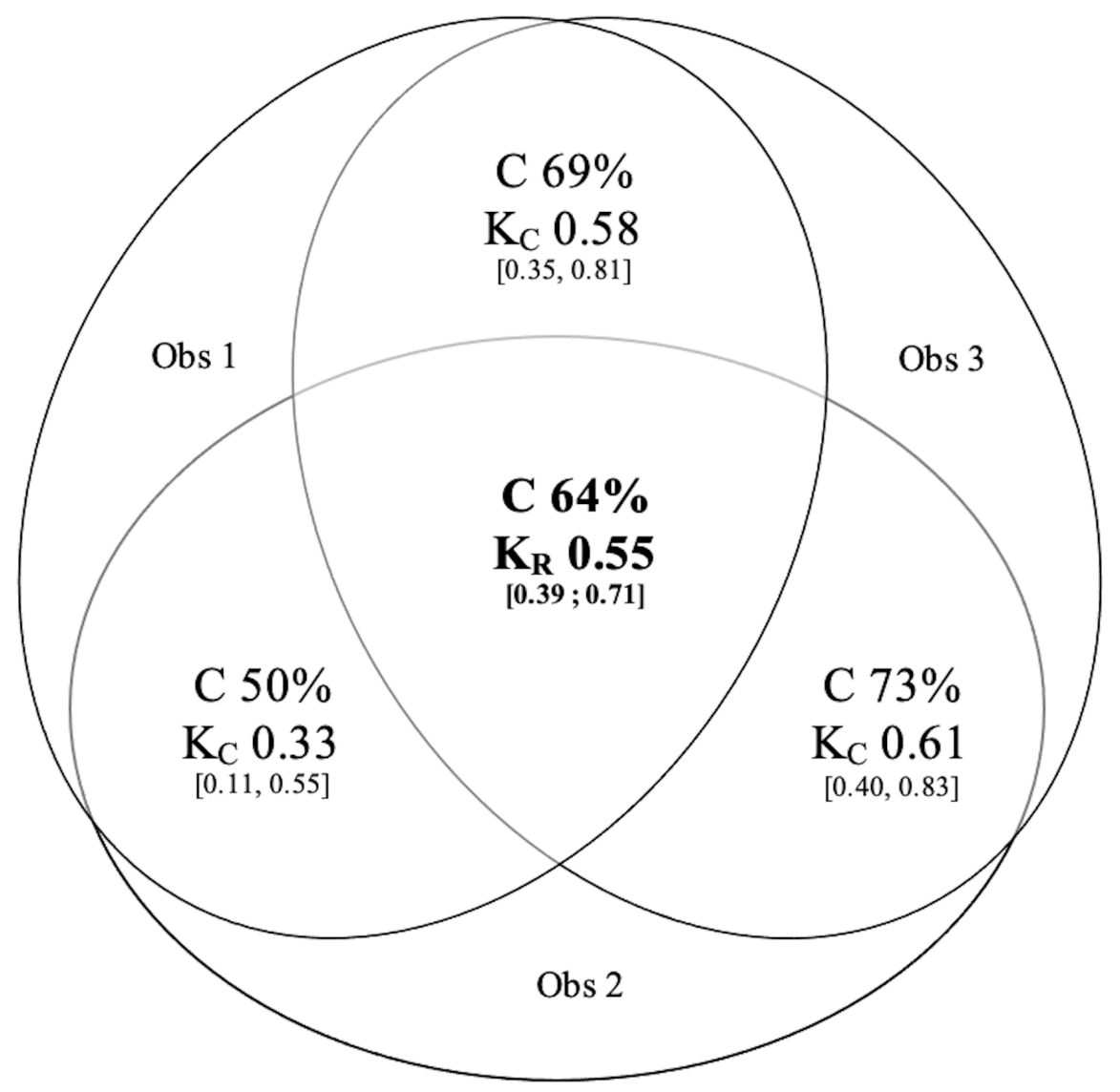




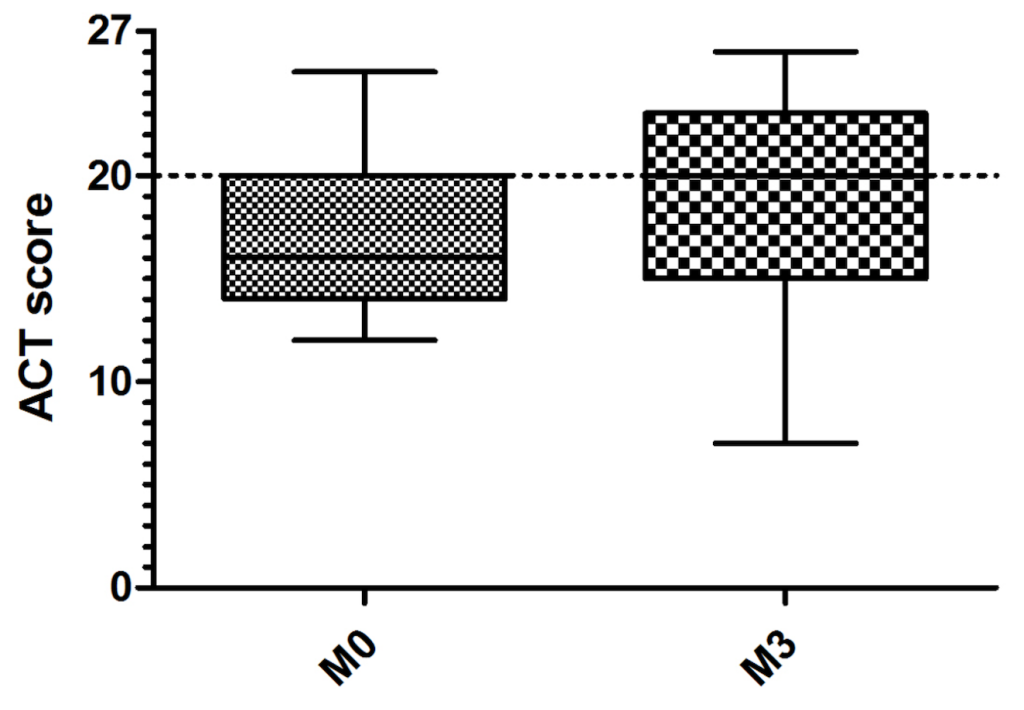



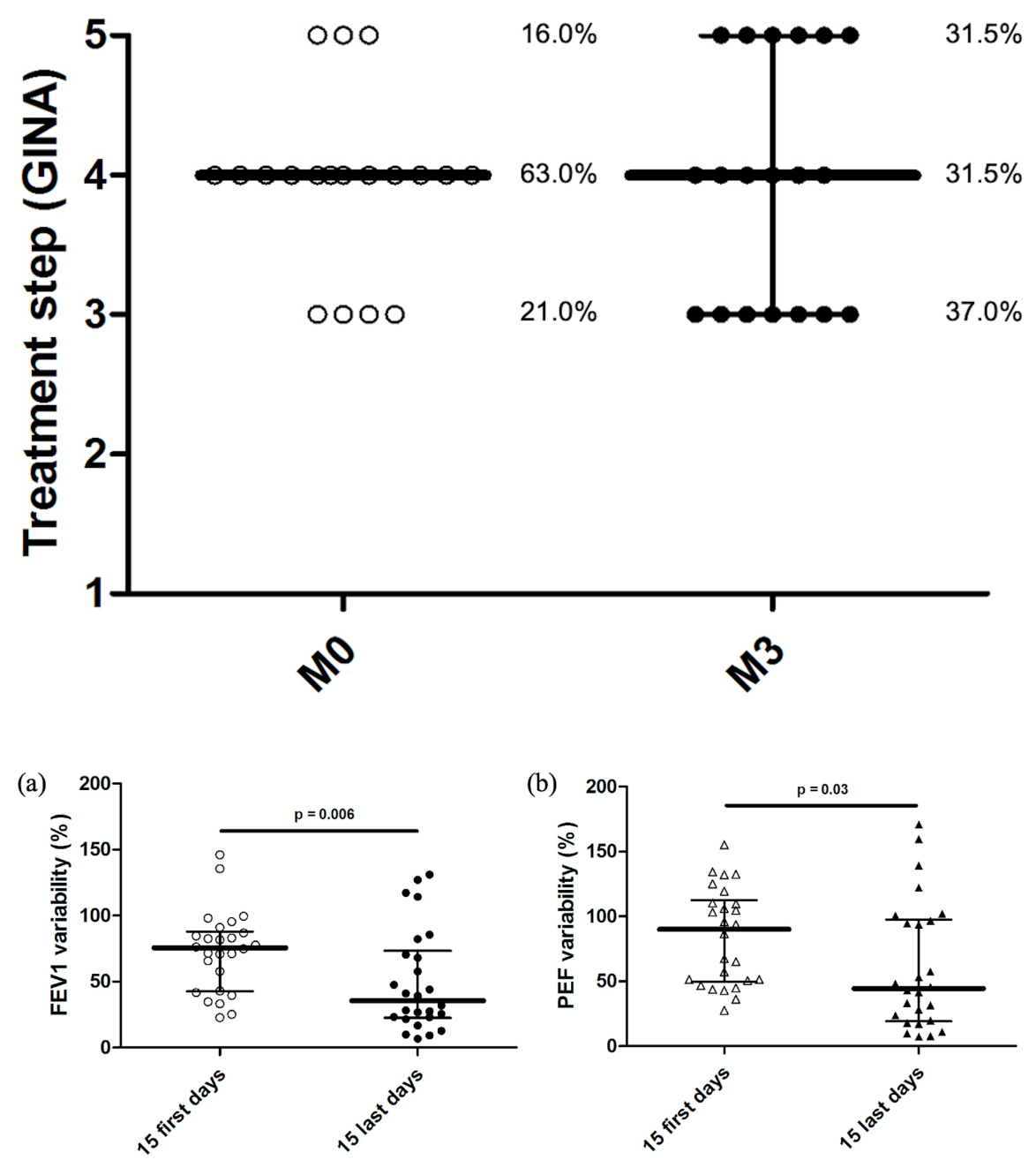